\title{
Characterization of PiB Binding to White Matter in Alzheimer Disease and Other Dementias
}

\author{
Michelle T. Fodero-Tavoletti ${ }^{1-3}$, Christopher C. Rowe ${ }^{4,5}$, Catriona A. McLean ${ }^{6}$, Laura Leone ${ }^{1}$, Qiao-Xin Li ${ }^{1,3}$, \\ Colin L. Masters ${ }^{2,3,7,8}$, Roberto Cappai ${ }^{* 1-3}$, and Victor L. Villemagne* ${ }^{* 1,3-5}$ \\ ${ }^{1}$ Department of Pathology, University of Melbourne, Victoria, Australia; ${ }^{2}$ Bio21 Molecular and Biotechnology Institute, \\ Neuroproteomics Platform, University of Melbourne, Victoria, Australia; ${ }^{3}$ Mental Health Research Institute of Victoria, Parkville, \\ Victoria, Australia; ${ }^{4}$ Department of Nuclear Medicine, Centre for PET, Austin Hospital, Heidelberg, Victoria, Australia; \\ ${ }^{5}$ Department of Medicine (Austin Hospital), University of Melbourne, Victoria, Australia; ${ }^{6}$ Department of Anatomical Pathology, \\ Monash University and Alfred Hospital, Prahran, Victoria, Australia; ${ }^{7}$ National Neuroscience Facility, University of Melbourne, \\ Victoria, Australia; and ${ }^{8}$ Centre for Neuroscience, University of Melbourne, Victoria Australia
}

\begin{abstract}
${ }^{11} \mathrm{C}$-Pittsburgh Compound B $\left({ }^{11} \mathrm{C}-\mathrm{PiB}\right) \mathrm{PET}$ has demonstrated significantly higher $\mathrm{PiB}$ retention in the gray matter of Alzheimer disease (AD) patients than in healthy controls (HCs). PiB is similarly retained within the white matter of $H C$ and $A D$ brains. Although the specificity of $\mathrm{PiB}$ for $\mathrm{A} \beta$ plaques in gray matter has been well described, the nature of $\mathrm{PiB}$ binding to white matter remains unclear. In this study, we characterized the binding of $\mathrm{PiB}$ to human white matter homogenates. Methods: In vitro binding studies were conducted using ${ }^{3} \mathrm{H}-\mathrm{PiB}(0.1-500 \mathrm{nM})$ and white matter brain homogenates $(100 \mu \mathrm{g})$ from $3 \mathrm{AD}$ patients and $3 \mathrm{HCs}$. Nonspecific binding was determined using $\mathrm{PiB}(1 \mu \mathrm{M})$. White matter from the same patients was also analyzed by immunofluorescence/immunohistochemistry (IF/lHC) microscopy and Western blotting for $A \beta$ expression. White matter kinetics were also characterized in vivo through ${ }^{11} \mathrm{C}-\mathrm{PiB}$ PET studies in 27 $\mathrm{HCs}$ and 34 patients with dementia. IF/IHC experiments were conducted on 1 postmortem patient with dementia, to compare with the ${ }^{11} \mathrm{C}-\mathrm{PiB}$ distribution volume ratio data acquired 23 mo earlier. Results: In vitro saturation studies indicated that ${ }^{3} \mathrm{H}-$ $\mathrm{PiB}$ binds nonspecifically to white matter brain homogenates. $\mathrm{PiB}$ fluorescence staining of $\mathrm{AD}$ and $\mathrm{HC}$ brain sections was consistent with absence of $A \beta$ in IHC staining. Higher gray matterto-white matter ratios were observed in IHC images than in ${ }^{11} \mathrm{C}-\mathrm{PiB}$ PET images. Conclusion: These studies suggest that $\mathrm{PiB}$ binding to white matter is mainly nonsaturable and nonspecific and that $\mathrm{PiB}$ retention in the ${ }^{11} \mathrm{C}-\mathrm{PiB}$ PET studies is largely attributable to slower $\mathrm{PiB}$ white matter kinetics.
\end{abstract}

Key Words: Pittsburgh Compound-B; Alzheimer disease; white matter; $A \beta$; PET

J Nucl Med 2009; 50:198-204

DOI: 10.2967/jnumed.108.057984

Received Sep. 9, 2008; revision accepted Nov. 14, 2008 For correspondence or reprints contact: Victor L. Villemagne, Department of Nuclear Medicine, Centre for PET, Austin Hospital, 145 Studley Rd., Heidelberg, Victoria, Australia 3084.

E-mail: villemagne@petnm.unimelb.edu.au

${ }^{*}$ Contributed equally to this work.

COPYRIGHT @ 2009 by the Society of Nuclear Medicine, Inc.
$\mathbf{P}$ ittsburgh Compound B (PiB; 2-(4'-methylaminophenyl)6-hydroxybenzothiazole, or 6-OH-BTA-1), a derivative of thioflavin T, has been successfully used as a PET ligand to assess $A \beta$ deposition. PiB has provided quantitative information on $A \beta$ burden, leading to new insights into $A \beta$ deposition in the brain and facilitating research of neurodegenerative disease in which $\mathrm{A} \beta$ may play a role $(1-4)$. PET studies have shown not only a robust difference in ${ }^{11} \mathrm{C}$ $\mathrm{PiB}$ retention between age-matched healthy controls ( $\mathrm{HCs})$ and Alzheimer disease (AD) patients $(1,2,5)$ but also inverse correlations with glucose hypometabolism $(2,6)$ and decreased cerebrospinal fluid $A \beta_{42}$ (7) and rate of cerebral atrophy (as measured by MRI) (8). Furthermore, comparison of the diagnostic utility of $A \beta$ versus ${ }^{18} \mathrm{~F}$-FDG imaging demonstrated that $\mathrm{PiB}$ imaging is more accurate than is ${ }^{18} \mathrm{~F}$ FDG for the diagnosis of AD (9). Studies in patients with dementia with Lewy bodies (DLB) demonstrated an ${ }^{11} \mathrm{C}$ $\mathrm{PiB}$ retention pattern similar to that of $\mathrm{AD}$ patients (1). Nonetheless, average ${ }^{11} \mathrm{C}-\mathrm{PiB}$ PET retention in DLB brains was lower, reflecting a larger spectrum of $\mathrm{A} \beta$ deposition (1). Interestingly, about $20 \%-25 \%$ of the cognitively normal elderly subjects who were evaluated showed cortical binding predominantly in the prefrontal and posterior cingulate/ precuneus regions, though to a lesser degree than did $\mathrm{AD}$ patients $(1,10,11)$.

Despite the evidence demonstrating the specificity of $\mathrm{PiB}$ for $\mathrm{A} \beta$ plaques, critical analysis of ${ }^{11} \mathrm{C}$-PiB PET studies has warranted further investigations. First, the contribution of Lewy bodies (LBs) to ${ }^{11} \mathrm{C}-\mathrm{PiB}$ PET retention in DLB patients has been studied. LBs are primarily composed of aggregated $\alpha$-synuclein and, like $A \beta$, are thioflavin T-positive. Moreover, $\mathrm{LBs}$ reside in the same cortical brain regions as do $\mathrm{A} \beta$ plaques. We characterized ${ }^{3} \mathrm{H}-\mathrm{PiB}$ binding to $\alpha$-synuclein fibrils and LBs (12). Although ${ }^{3} \mathrm{H}-\mathrm{PiB}$ binds to $\alpha$-synuclein 
fibrils with lower affinity than to $A \beta_{1-42}$ fibrils, the concentration of $\alpha$-synuclein fibrils required for significant ${ }^{3} \mathrm{H}-\mathrm{PiB}$ binding is physiologically unattainable. Image quantification suggested that both the small size and low number of LBs present within cortical regions of DLB brains would make negligible their contribution to the ${ }^{11} \mathrm{C}-\mathrm{PiB}$ PET signal (12). Second, further research is warranted because of the apparent higher PiB retention in the white matter of HCs.

$\mathrm{PiB}$ retention has been reported to be equivalent in the white matter (a brain region relatively unaffected by amyloid deposition) of AD patients and HCs (2). To date, the specificity of $\mathrm{PiB}$ binding to white matter has not been examined. The aim of the present study was to characterize the in vitro and in vivo binding of $\mathrm{PiB}$ to white matter.

\section{MATERIALS AND METHODS}

\section{Chemicals}

All reagents were purchased from Sigma, unless otherwise stated. ${ }^{3} \mathrm{H}$-2-(4'-methylaminophenyl)-6-hydroxybenzothiazole ( ${ }^{3} \mathrm{H}-\mathrm{PiB}$; purity, $>97 \%$; specific activity, 2,679 $\mathrm{GBq} / \mathrm{mmol}$ ) was sourced from American Radiolabeled Chemicals. Unlabeled PiB was custom-synthesized, purified, and analyzed as described previously (13). Human $A \beta_{1-42}$ was purchased from W.M. Keck Laboratory.

\section{Tissue Collection and Characterization}

Brain tissue was collected at autopsy. Sourcing and preparation of human brain tissue was conducted by the National Neural Tissue Resource Centre. AD pathologic diagnosis was made according to standard National Institute on Aging-Reagan Institute criteria (14). Determination of age-matched HC cases was subject to the above criteria. The number of subjects is indicated in the figures and tables.

\section{Preparation of Human Brain Tissue for In Vitro Binding Studies}

Gray (frontal cortex) and white matter (centrum semiovale) was isolated from postmortem AD patients and HCs. Tissue was homogenized in $1 \times$ phosphate-buffered saline (PBS) (without calcium and magnesium), using an ultrasonic cell disrupter $(2 \times$ $30 \mathrm{~s}, 24,000 \mathrm{rpm}$ ) (Virsonic 600; Virtis). Protein concentration was determined (bicinchoninic acid assay), and brain homogenates were separated into aliquots and frozen $\left(-80^{\circ} \mathrm{C}\right)$.

\section{ELISA}

Brain A $\beta$ levels were determined using the DELFIA Double Capture ELISA (PerkinElmer), as previously described (15). Brain tissue, as prepared above, was solubilized with guanidine hydrogen chloride $(5 \mathrm{M})$, followed by centrifugation $(16,000 \mathrm{~g}$ for 20 min). Supernatants were then diluted 1:10 with blocking buffer ( $0.25 \%$ casein or Superblock [Thermo Fisher Scientific Inc.] in PBS, with $0.025 \%$ polysorbate-20), and aliquots were placed onto the plate. Plates were incubated with either $G 210$ (to detect $A \beta_{1-40}$ ) or G211 (A $\left.\beta_{1-42}\right)$ antibodies and then blocked with $0.5 \%(\mathrm{w} / \mathrm{v})$ casein and PBS or Superblock and PBS buffer $(\mathrm{pH}$ 7.4). After washing, WO2-biotin was added. $A \beta_{1-40}$ and $A \beta_{1-42}$ peptide standards and samples were assayed in triplicate and incubated overnight $\left(4^{\circ} \mathrm{C}\right)$. Plates were washed, and europium-labeled streptavidin was added and developed with enhancement solution. Analysis was performed using the Wallac Multilabel Plate Reader
(PerkinElmer), with excitation and emission at 340 and $613 \mathrm{~nm}$, respectively.

\section{In Vitro PiB Binding Assays}

$\mathrm{AD}$ and age-matched control brain homogenates $(100 \mu \mathrm{g})$ were incubated with increasing concentrations of ${ }^{3} \mathrm{H}-\mathrm{PiB}(0.1-200 \mathrm{nM}$; specific activity, 2,679 $\mathrm{GBq} / \mathrm{mmol}$ ). Nonspecific binding was accounted for using unlabeled PiB $(1 \mu \mathrm{M})$. Binding reactions were incubated at room temperature for $3 \mathrm{~h}$ in $200 \mu \mathrm{L}$ of assay buffer (PBS, minus magnesium and calcium ions [JRH Biosciences] and $0.1 \%$ bovine serum albumin). Bound radioactivity was separated from free radioactivity by filtration under reduced pressure (MultiScreen HTS Vacuum Manifold and MultiScreen HTS 96-well filtration plates [0.65 $\mu \mathrm{m}]$; Millipore). Filters were washed 3 times with $200 \mu \mathrm{L}$ of assay buffer and incubated overnight in $3 \mathrm{~mL}$ of scintillation fluid (Emulsifier Safe Scintillation cocktail; PerkinElmer). Samples were counted in a $\beta$-counter (LS6500; Beckman Coulter). Binding data were analyzed with curve-fitting software (version 1.0, GraphPad Prism; GraphPad Software). All experiments were conducted in triplicate.

\section{Immunohistochemistry (IHC) and Immunofluorescence (IF) Analysis}

The brain sections (frontal cortex or centrum semiovale) of $\mathrm{AD}$ patients and HCs were fixed (10\% formalin/PBS) and embedded in paraffin. Serial sections $(7 \mu \mathrm{m})$ were freed of paraffin and treated with $80 \%$ formic acid ( $5 \mathrm{~min}$ ), and endogenous peroxidase activity was blocked (3\% hydrogen peroxide). Sections were blocked (20\% fetal calf serum, $50 \mathrm{mM}$ Tris- $\mathrm{HCl}, 175 \mathrm{mM}$ sodium chloride, $\mathrm{pH}$ 7.4) before incubation with $\mathrm{A} \beta$ (1E8; $\mathrm{A} \beta$ epitope 17$22(16))$ primary antibody for $1 \mathrm{~h}$ at room temperature. Antibody reactivity was visualized using a labeled streptavidin-biotin kit (Dako), and hydrogen-peroxidase-diaminobenzidine was used to visualize $A \beta$-positive deposits. The second serial section was stained with $\mathrm{PiB}$. This section was freed of paraffin and autofluorescence was quenched $(0.25 \%$ potassium permanganate/PBS, $20 \mathrm{~min} ; 1 \%$ potassium metabisulfite/1\% oxalic acid/PBS, $5 \mathrm{~min}$ ). Sections were blocked in $2 \%$ bovine serum albumin/PBS ( $\mathrm{pH} 7.0$, $10 \mathrm{~min}$ ) and stained with $100 \mu \mathrm{M} \mathrm{PiB}$ for $30 \mathrm{~min}$. Washed (PBS) sections were mounted in nonfluorescent mounting medium (Dako), and stained tissue sections were analyzed using a microscope (model DM1RB; Leica). Colocalization of PiB and antibody signals was assessed by overlaying images from each of the stained serial tissue sections.

\section{In Vivo Amyloid Imaging Studies}

A total of 54 subjects (27 HCs and $17 \mathrm{AD}$ and $10 \mathrm{DLB}$ patients) were recruited for the study and underwent ${ }^{11} \mathrm{C}$-PiB PET scans. All AD and DLB patients met National Institute of Neurological and Communicative Disorders and Stroke and the Alzheimer's Disease and Related Disorders Association criteria and consensus criteria for probable AD (17) and DLB (18) diagnosis, respectively. Patients were recruited from the Austin Health Memory Disorders and Neurobehavioural Clinics. Written informed consent for participation in this study was obtained before the scan. Approval was obtained for the study from the Austin Health Human Research Ethics Committee, Austin Radiation Subcommittee, and the Victorian Department of Human Services Radiation Safety Unit. All subjects underwent 3-dimensional spoiled gradient echo T1-weighed MRI on a 1.5-T scanner (Sigma; GE Healthcare) for screening and subsequent coregistration with PET images. ${ }^{11} \mathrm{C}-\mathrm{PiB}$ was produced in the Centre for PET, Austin 
Hospital, as previously described (1). Attenuation correction was performed using a rotation transmission sinogram acquisition in 3-dimensional mode, with a single ${ }^{137} \mathrm{Cs}$ point source, before the injection of the radiotracer. A 90-min list-mode emission acquisition was performed in 3-dimensional mode with a PET camera (Allegro; Phillips) after an intravenous injection of ${ }^{11} \mathrm{C}-\mathrm{PiB}$ $(375 \pm 18 \mathrm{MBq}$ ) (specific activity, $30 \pm 7.5 \mathrm{GBq} / \mu \mathrm{mol}[30,000$ $\mathrm{Gbq} / \mathrm{mmol}$ (1)). List-mode raw data were sorted offline into $4 \times$ $30 \mathrm{~s}, 9 \times 1 \mathrm{~min}, 3 \times 3 \mathrm{~min}, 10 \times 6 \mathrm{~min}$, and $2 \times 10 \mathrm{~min}$ frames. The sorted sinograms were reconstructed using a 3-dimensional rowaction maximization-likelihood algorithm. Coregistration of the PET images with individual MR images was performed with statistical parametric mapping (SPM2; MRC Cognition and Brain Sciences Unit) (19). Regions of interest (ROIs) were drawn on individual MR images and transferred to the coregistered PET images. Mean radioactivity values were obtained from the ROIs for cortical, subcortical, and white matter regions, and decaycorrected time-activity curves were generated. Distribution volume ratios (DVRs) were determined via graphical analysis (20), using the cerebellar cortex as the input function $(2,20,21)$. The mean of the DVRs for frontal, cingulate, parietal, lateral temporal, and occipital cortices was calculated and termed neocortical DVR. Because there were no significant differences in DVR between the groups, brain clearances of the radiotracer were calculated by fitting all the regional radioactivity concentration values at the different time points to a triple-exponential equation:

$$
\mathrm{E}_{(\mathrm{t})}=\mathrm{Ae}^{-\alpha \mathrm{t}}+\mathrm{Be}^{-\beta \mathrm{t}}+\mathrm{Ce}^{-\gamma \mathrm{t}},
$$

where $\mathrm{E}$ is the brain radioactivity concentration, and $\mathrm{A}, \mathrm{B}$, and $\mathrm{C}$ are coefficients for the initial rapid distribution $(\alpha)$, distribution and disposition $(\beta)$, and elimination $(\gamma)$ phases, respectively. The clearance half-life $\left(\mathrm{t}_{1 / 2}\right)$ was calculated as $\mathrm{t}_{1 / 2}=0.693 / \gamma$.

\section{Postmortem In Vivo Comparison}

IF/IHC was compared with ${ }^{11} \mathrm{C}-\mathrm{PiB}$ DVR in a DLB patient who had died 23 mo after the PET scan and whose brain was neuropathologically evaluated after autopsy. Images were quantified in the immunostained brain cortical (frontal and temporal cortex) and white matter (centrum semiovale) sections. Serial 5 - $\mu \mathrm{m}$ tissue sections were immunostained with antibodies to $\mathrm{A} \beta$ (1E8), $\alpha$-synuclein $(97 / 8(22)$ ), and tau-protein (Dako), as previously described (12). A total of 45 high-resolution ( $\sim 1.2$ pixel/ $\mu \mathrm{m}), 24$-bit red-green-blue color brain images, from 5 regions in each section, were acquired and digitized using an axiocam HRc (12-megapixel) color digital camera (Zeiss). Images were quantified using ImagePro Plus software (version 5.1; Media Cybernetics). For each image, an ROI was drawn around the margins of the brain tissue under the field of view. IHC-positive structures were identified, and thresholds were applied using color selection to separate plaques, neurofibrillary tangles, or Lewy bodies from background tissue. Only structures larger than 10 pixels were included. Data were expressed as the fraction of the area of IHC-positive pixels in each section to the total brain area in the same section.

\section{Statistical Analysis}

Descriptive statistics and ANOVA were performed to assess group differences in the in vitro studies. For PET studies, group differences were statistically evaluated using a Wilcoxon signed rank test followed by a Dunnet's test to compare each group with controls and a Tukey-Kramer honestly significant difference test to establish differences between group means. Correlations were assessed by Pearson product-moment or Spearman rank-order correlation analyses where appropriate.

\section{RESULTS}

\section{In Vitro ${ }^{3} \mathrm{H}-\mathrm{PiB}$ Binding Analysis of Human AD and HC Brains}

In previous studies, postmortem brain homogenates have been used to characterize amyloid imaging agents $(13,23)$. To determine the contribution of $\mathrm{PiB}$ binding to white matter in ${ }^{11} \mathrm{C}-\mathrm{PiB}$ PET studies, ${ }^{3} \mathrm{H}-\mathrm{PiB}$ binding to centrum semiovale homogenates was assessed. The centrum semiovale region was chosen to ensure no gray matter contamination. In parallel, the same experiments were repeated with gray matter homogenates (frontal cortex) from the same subjects. As previously reported, ${ }^{3} \mathrm{H}-\mathrm{PiB}$ bound with high affinity to AD gray matter (Fig. 1A) (24). Nevertheless, ${ }^{3} \mathrm{H}-\mathrm{PiB}$ failed to show specific binding to $\mathrm{HC}$ gray matter (Fig. 1B) or to $\mathrm{AD}$ and $\mathrm{HC}$ white matter homogenates (Figs. $1 \mathrm{C}$ and $1 \mathrm{D}$, respectively). ${ }^{3} \mathrm{H}-\mathrm{PiB}$ binding to AD gray matter homogenates was associated with the presence of $A \beta$ expression, as determined by ELISA (Table 1) and Western blot (data not shown). Furthermore, the absence of ${ }^{3} \mathrm{H}-\mathrm{PiB}$ binding was consistent with negligible detection of $A \beta$ expression in these homogenates (Table 1).

\section{PiB and Immunohistochemical Staining of Human AD Patients and HCs}

As a qualitative measure of $\mathrm{PiB}$ binding, unlabeled $\mathrm{PiB}$ (100 $\mu \mathrm{M})$ staining of fixed tissue was compared with

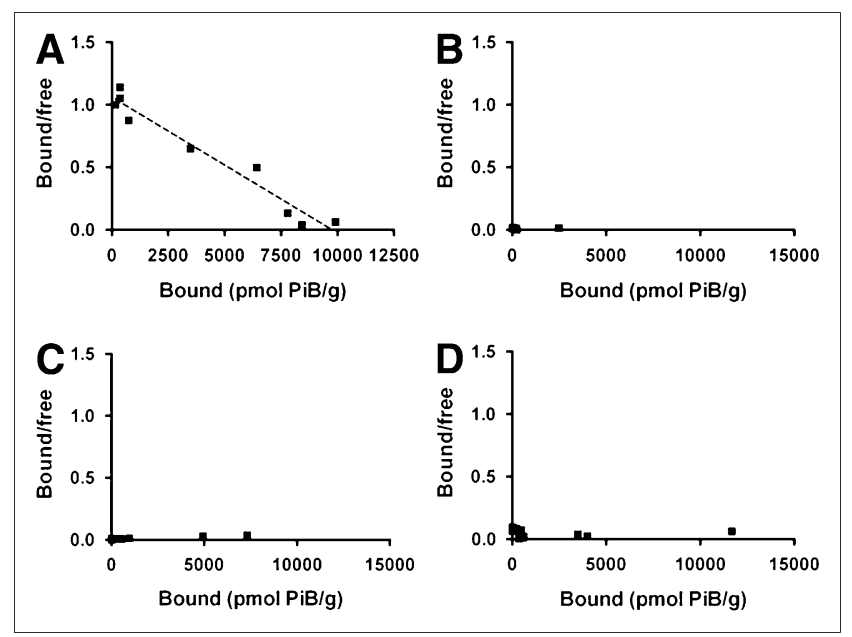

FIGURE 1. In vitro binding studies demonstrate that ${ }^{3} \mathrm{H}-\mathrm{PiB}$ fails to bind to white matter brain homogenates. Scatchard plots of ${ }^{3} \mathrm{H}-\mathrm{PiB}$ binding to gray matter (AD patients [A] and agematched $\mathrm{HCs}[\mathrm{B}]$ ) and white matter (AD patients $[\mathrm{C}]$ and agematched HCs [D]) brain homogenates. Scatchard analysis indicated that ${ }^{3} \mathrm{H}-\mathrm{PiB}$ binds to $\mathrm{AD}$ gray matter (dissociation constant, $3.77 \mathrm{nM}$; maximum number of binding sites, 9,254 pmol ${ }^{3} \mathrm{H}-\mathrm{PiB} / \mathrm{g}$ tissue) brain homogenates. No significant binding of ${ }^{3} \mathrm{H}-\mathrm{PiB}$ to $\mathrm{HC}$ gray matter or white matter homogenates was observed. Consequently, no binding parameters could be calculated. Binding data were analyzed using software (version 1.0; GraphPad). Figure is representative of at least 3 independent experiments. 
TABLE 1. ELISA Analysis of $A \beta$ in Human Brain Tissue Homogenates

\begin{tabular}{lrrr} 
Tissue & $\mathrm{A} \beta_{1-40}(\mathrm{pmol} / \mathrm{g}$ protein) & $\mathrm{A} \beta_{1-42}$ (pmol/g protein) & Total $\mathrm{A} \beta$ (pmol/g protein) \\
White matter (centrum semiovale) & & & $16.35 \pm 3.0$ \\
AD $(n=3)$ & $2.98 \pm 0.13$ & $13.37 \pm 2.87$ & $8.89 \pm 5.5$ \\
HC $(n=3)$ & $0.77 \pm 0.05$ & $8.12 \pm 5.46$ & $1,210.0 \pm 376.0$ \\
Gray matter (frontal cortex) & $128.0 \pm 39.0$ & $1,082.0 \pm 337.0$ & $8.81 \pm 0.74$ \\
AD $(n=3)$ & $4.61 \pm 0.13$ & $4.20 \pm 0.61$ & \\
HC $(n=3)$ & & & \\
\hline
\end{tabular}

contiguous IHC-immunostained sections. As previously reported, AD frontal cortex sections exhibited numerous $\mathrm{A} \beta$ plaques that colocalized with $\mathrm{PiB}$ staining (Fig. 2A) (12). The absence of $A \beta$ plaques was evident in the centrum semiovale sections from both $\mathrm{AD}$ and $\mathrm{HC}$ tissue sections (Figs. 2B and 2C, respectively). Nevertheless, at high magnification, $\mathrm{PiB}$ staining of the centrum semiovale appeared to highlight blood vessels in both subjects.

\section{In Vivo ${ }^{11} \mathrm{C}-\mathrm{PiB}$ PET}

Group demographics are depicted in Table 2. ${ }^{11} \mathrm{C}-\mathrm{PiB}$ brain radioactivity peaked between 3 and 6 min after injection, and binding appeared to be reversible. ${ }^{11} \mathrm{C}-\mathrm{PiB}$ cleared most quickly from the cerebellum and most slowly from the white matter (Fig. 3). Clearance from the cere- bellar cortex was the same for all groups, a finding that is consistent with the absence of neuritic $A \beta$ plaques in this region (25). Although neocortical ${ }^{11} \mathrm{C}-\mathrm{PiB}$ clearance was significantly slower in AD and DLB patients than in $\mathrm{HCs}$, there were no differences in white matter clearance between the groups (Table 2).

As previously reported (1), AD patients showed marked cortical and caudate nucleus ${ }^{11} \mathrm{C}-\mathrm{PiB}$ retention, with relative sparing of the sensorimotor cortex. DLB patients showed cortical ${ }^{11} \mathrm{C}-\mathrm{PiB}$ retention similar to that of $\mathrm{AD}$ patients, albeit the degree of binding was generally lower and widely varied among DLB patients (Table 2). Most $\mathrm{HCs}$ showed less ${ }^{11} \mathrm{C}-\mathrm{PiB}$ retention in all cortical and subcortical gray matter areas, compared with white matter. Furthermore, $23 \%$ of HCs showed a range of higher cortical
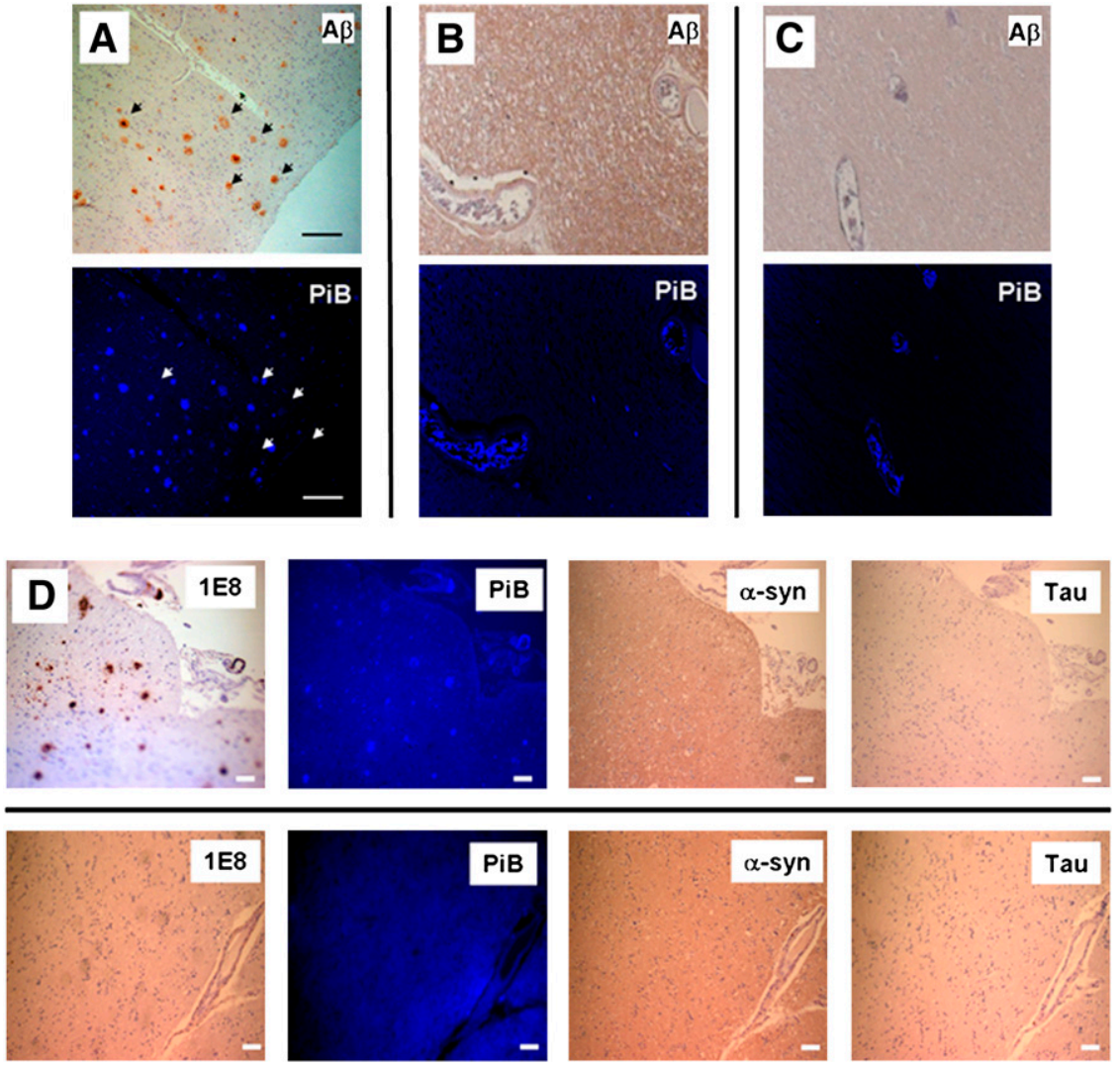
with any reagent used, indicating absence of $A \beta$ plaques, Lewy bodies, or neurofibrillary tangles. Images were taken on Leica microscope. Scale bars, $50 \mu \mathrm{m}$. $\alpha$-syn $=\alpha$-synuclein.

FIGURE 2. IHC and IF analysis indicates PiB staining does not bind to white matter. Microscopy images of 2 serial sections $(7 \mu \mathrm{m})$ from frontal cortex of $A D$ patient $(A)$ and centrum semiovale from age-matched $\mathrm{HC}(\mathrm{B})$ and $\mathrm{AD}$ patient $(\mathrm{C})$. First section was immunostained with antibody to $A \beta$ (1E8) to identify $A \beta$ plaques; second serial section was stained with $100 \mu \mathrm{M}$ PiB. Presence of $A \beta$ plaques was detected in $\mathrm{AD}$ frontal cortex sections (black arrowheads) and colocalized with positive PiB staining (white arrowheads). Centrum semiovale sections exhibited no immunoreactivity with 1E8, indicating absence of plaques (B and $\mathrm{C}$ ). At higher magnification, $\mathrm{PiB}$ staining was observed to highlight blood vessels. (D) Serial sections $(5 \mu \mathrm{m})$ isolated from gray matter (frontal cortex; top) and white matter (centrum semiovale; bottom) of patient with DLB who underwent ${ }^{11} \mathrm{C}$ PiB PET 23 mo before his death. Sections (from left to right) were stained with antibodies to $A \beta$ (1E8) to $A \beta$ plaques, $P i B$, $\alpha$-syn (97/8), and tau-protein (Dako) and stained with $\mathrm{PiB}(100 \mu \mathrm{M})$. Presence of $A \beta$ plaques was detected in DLB frontal cortex sections and colocalized with positive $\mathrm{PiB}$ staining. Centrum semiovale sections exhibited no immunoreactivity

microscope. Scale bars, $50 \mu \mathrm{m}$. $\alpha$-syn $=\alpha$-synuclein.

PiB Binding to White Matter • Fodero-Tavoletti et al. 
TABLE 2. Group Mean Demographic Data and PiB DVRs and Clearance Values in Aging HCs and Patients

with Dementia

\begin{tabular}{|c|c|c|c|}
\hline \multirow[b]{2}{*}{ Demographic data } & \multicolumn{3}{|c|}{ PiB DVR and clearance value } \\
\hline & $\mathrm{HCs}(n=27)$ & AD patients $(n=17)$ & DLB patients $(n=10)$ \\
\hline Age (y) & $72.6 \pm 6.9$ (range, 59-84) & $74.0 \pm 11.3($ range, $56-91)$ & $72.0 \pm 5.4$ (range, 63-81) \\
\hline Female:male & $13: 14$ & $9: 8$ & $2: 8$ \\
\hline Education $(\mathrm{y})$ & $12.5 \pm 3.5$ & $12.3 \pm 4.8$ & $9.3 \pm 0.9$ \\
\hline MMSE & $29.2 \pm 0.9$ & $22.1 \pm 5.5^{\star}$ & $20.8 \pm 7.2^{*}$ \\
\hline Clinical dementia rating & $0.0 \pm 0.0$ & $1.2 \pm 0.7^{*}$ & $1.6 \pm 0.8^{*}$ \\
\hline ApoE $\varepsilon 4 /$ non $\varepsilon 4$ & $8 / 19$ & $10 / 7$ & $7 / 3$ \\
\hline Neocortical $^{\dagger}$ DVR & $1.22 \pm 0.21$ & $1.99 \pm 0.23^{\star}$ & $1.67 \pm 0.32^{* \neq}$ \\
\hline White matter DVR & $1.39 \pm 0.19 \S$ & $1.36 \pm 0.24 \S$ & $1.33 \pm 0.36$ \\
\hline Neocortical clearance $t_{1 / 2}(\mathrm{~min})$ & $68.7 \pm 11.6$ & $112.5 \pm 28.3^{*}$ & $94.6 \pm 25.7^{\star}$ \\
\hline White matter clearance $t_{1 / 2}$ (min) & $224.4 \pm 89.9 \S$ & $268.7 \pm 98.7 \S$ & $229.1 \pm 107.0 \S$ \\
\hline \multicolumn{4}{|c|}{$\begin{array}{l}\text { *Statistically significant results, compared with controls }(P<0.05) \text {. } \\
{ }^{\dagger} \text { Neocortex comprises average DVR values for frontal, parietal, cingulate, occipital, and lateral temporal cortices. } \\
{ }^{\ddagger} \text { Statistically significant results for DLB patients, compared with AD patients }(P<0.05) \text {. } \\
\text { \$Statistically significant results for white matter, compared with gray matter }(P<0.05) \text {. } \\
\text { ApoE = apolipoprotein E. }\end{array}$} \\
\hline
\end{tabular}

${ }^{11} \mathrm{C}-\mathrm{PiB}$ binding in gray matter (Table 2 ). No correlation ( $r=0.12, P=0.32$ ) was found between ${ }^{11} \mathrm{C}-\mathrm{PiB}$ DVRs in the neocortex and white matter (data not shown).

IF/IHC analysis of brain sections from a DLB patient, who died 23 mo after an initial ${ }^{11} \mathrm{C}$-PiB PET scan, indicated that the highest area of plaques was in the frontal cortex, with no plaques detected in the white matter (IHC-positive area fraction, 0.03 and 0.00 , respectively) (Fig. 2D). Although there were also LBs and even some neurofibrillary tangles present in other cortical areas (not shown), there were none in the white matter (Fig. 2D). Although A $\beta$ plaques were not detectable by IHC or IF in white matter, ${ }^{11} \mathrm{C}$-PiB standardized uptake values were only $11 \%$ higher in the neocortical gray matter areas than in the white matter (standardized uptake values, 1.48 and 1.33, respectively).

\section{DISCUSSION}

We used in vitro and in vivo methods to characterize ${ }^{11} \mathrm{C}$ PiB PET binding in white matter. In vitro approaches were used to assess whether ${ }^{3} \mathrm{H}-\mathrm{PiB}$ specifically bound to brain homogenates or sections isolated from the centrum semiovale of AD patients and HCs. ELISA data suggested that the presence of $A \beta$ in the centrum semiovale was comparable to the levels of $A \beta$ detected in gray matter homogenates of HCs. Furthermore, the binding of ${ }^{3} \mathrm{H}-\mathrm{PiB}$ to the centrum semiovale homogenates of both $\mathrm{HCs}$ and $\mathrm{AD}$ patients was nonsaturable. IHC experiments also indicated the absence of $A \beta$ neuritic or diffuse plaques in the centrum semiovale. Additionally, correlation of ${ }^{11} \mathrm{C}-\mathrm{PiB}$ PET data with postmortem sections obtained almost $2 \mathrm{y}$ after the PET scan suggested that ${ }^{11} \mathrm{C}$-PiB PET retention in white matter was nonspecific binding, as, in addition to the notable absence of $\mathrm{A} \beta$ plaques, $\mathrm{PiB}$ failed to stain the centrum semiovale brain sections obtained at autopsy.
Although the concentration of $\mathrm{PiB}$ used in IF experiments was considerably higher $(100 \mu \mathrm{M})$ than the low nanomolar concentrations of in vivo PET studies $(1,26)$, these experiments revealed that in the absence of plaques, $\mathrm{PiB}$ accumulation was limited to highlighting blood vessels. In the absence of congophilic angiopathy, perivascular accumulation of $\mathrm{PiB}$ has been previously reported as representing either a nonspecific interaction $(27,28)$ or an artifact (28).

Graphical analysis of ${ }^{11} \mathrm{C}-\mathrm{PiB}$ PET data demonstrated no significant difference in white matter DVR values between HCs and patients with dementia. As previously reported (21), there was no correlation between neocortical and white matter DVRs, also suggesting that the retention in white matter is nonspecific. DVR values in white matter are higher than 1, potentially indicating some degree of specific binding. Furthermore, on average, white matter DVR values are higher than neocortical DVR values in HCs. There is increased accumulation of interstitial fluid in the white matter of $\mathrm{AD}$ patients (27). This increase could translate into increased accumulation of unbound (free) ${ }^{11} \mathrm{C}-\mathrm{PiB}$ in AD patients. Neither ${ }^{11} \mathrm{C}-\mathrm{PiB}$ DVR nor clearance from white matter in $\mathrm{AD}$ patients was significantly different from HCs or patients with other dementias, making it unlikely that ${ }^{11} \mathrm{C}-\mathrm{PiB}$ retention is a consequence of these reported increases in interstitial fluid. Previous reports suggest that messenger RNA expression of $A \beta$ precursor protein (APP) isoforms is 2-fold higher in the white matter of both HCs and AD patients than in the gray matter (29). APP plays an important role in response to injury (30); the expression of both $\mathrm{A} \beta$ and APP is increased in white matter after brain trauma (31), sometimes presenting diffuse $\mathrm{A} \beta$ deposits similar to those observed in healthy elderly and AD individuals. Binding to APP has also been proposed as an explanation for ${ }^{11} \mathrm{C}-\mathrm{PiB}$ retention in white matter. 


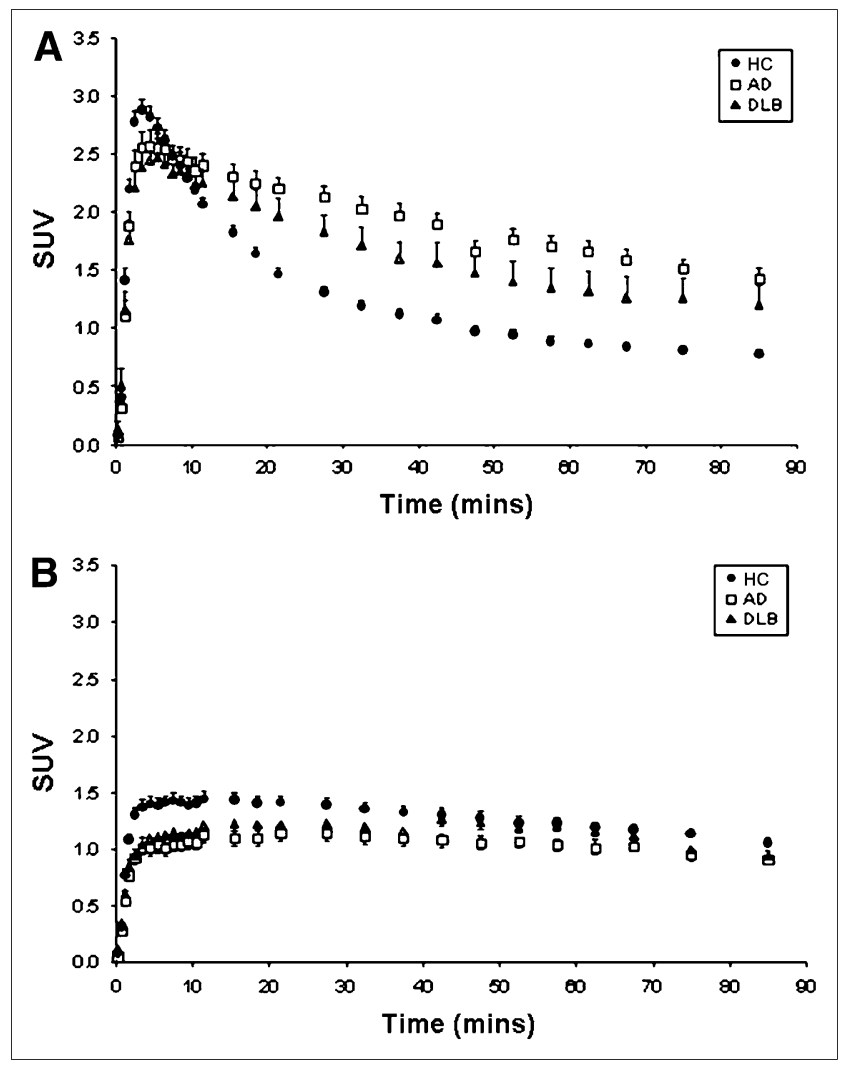

FIGURE 3. Time-activity curves demonstrate no difference in ${ }^{11} \mathrm{C}$-PiB clearance rates in white matter of all patients analyzed. Time-activity curves demonstrate uptake and clearance of ${ }^{11} \mathrm{C}-\mathrm{PiB}$ in frontal cortex $(\mathrm{A})$ and white matter (B). There is greater retention of $\mathrm{PiB}$ in frontal cortex of $A D$ patients and to lesser extent in DLB patients than in HCs. In contrast, there was no significant difference in rate of ${ }^{11} \mathrm{C}-\mathrm{PiB}$ clearance in all groups analyzed. SUV = standardized uptake value.

Recent MRI studies have shown not only reductions in the white matter volumes in AD patients (32) but also mainly reductions in fractal and relative anisotropy as assessed by diffusion tensor imaging, suggestive of Wallerian degeneration or regression of axonal processes associated with neuronal death $(33,34)$. Axonal damage and vascular degenerative disease are usually accompanied by increases in APP (35). Nevertheless, in the present study no significant differences were found in white matter DVR values between AD patients and HCs. Western blot analysis indicated that despite very high concentrations of APP in the white matter of both $\mathrm{HCs}$ and $\mathrm{AD}$ patients, no specific binding was detected in respective brain homogenates, and no $\mathrm{A} \beta$ deposition was visualized by either IHC or IF. Clearance rates for white matter, despite being significantly slower than those for gray matter, were no different among $\mathrm{HCs}$ and AD and DLB patients. Regional cerebral blood flow in white matter is 2.0-2.4 times lower than regional cerebral blood flow in the neocortex (36). Delays in delivery (37) and slower clearance of tracers (38) are typically described in white matter regions; therefore, slower ${ }^{11} \mathrm{C}$ -
PiB clearance from white matter may contribute to a DVR value higher than 1 in all subjects examined. Furthermore, in all subjects examined, ${ }^{11} \mathrm{C}-\mathrm{PiB}$ clearance in gray matter was significantly faster than in white matter regions. As in the case of HCs, before the end of the 90-min PET scan, the retention in gray matter is much lower than in white matter, giving the impression that white matter retention in $\mathrm{HCs}$ is higher than that in the other groups.

\section{CONCLUSION}

Our studies demonstrate that ${ }^{3} \mathrm{H}-\mathrm{PiB}$ binds nonspecifically to white matter in postmortem brain homogenates and fails to stain white matter tissue sections, suggesting that ${ }^{11} \mathrm{C}-\mathrm{PiB}$ retention in white matter is nonspecific and may be attributable to a slower regional clearance of the radiotracer.

\section{ACKNOWLEDGMENTS}

We thank Henri Tochon-Danguy, Graeme O'Keefe, Uwe Ackermann, Rachel Mulligan, Jessica Sagona, Kunthi Pathmaraj, Tim Saunder, Jason Bradley, and Gareth Jones for their crucial role during radiochemical synthesis, PET examinations, and image processing; Tiffany Cowie for ApoE genotyping; Katrina Laughton for ELISA processing; and Fairlie Hinton and Geoff Pavey from the National Neural Tissue Resource Centre for sourcing and preparing the human brain tissue. This work was supported in part by the National Health and Medical Research Council of Australia, the Austin Hospital Medical Research Foundation, and Neurosciences Victoria.

\section{REFERENCES}

1. Rowe $\mathrm{CC}, \mathrm{Ng} \mathrm{S}$, Ackermann U, et al. Imaging beta-amyloid burden in aging and dementia. Neurology. 2007;68:1718-1725.

2. Klunk WE, Engler H, Nordberg A, et al. Imaging brain amyloid in Alzheimer's disease with Pittsburgh Compound-B. Ann Neurol. 2004;55:306-319.

3. Engler H, Forsberg A, Almkvist O, et al. Two-year follow-up of amyloid deposition in patients with Alzheimer's disease. Brain. 2006;129:2856-2866.

4. Buckner RL, Snyder AZ, Shannon BJ, et al. Molecular, structural, and functional characterization of Alzheimer's disease: evidence for a relationship between default activity, amyloid, and memory. J Neurosci. 2005;25:7709-7717.

5. Kemppainen NM, Aalto S, Wilson IA, et al. Voxel-based analysis of PET amyloid ligand $\left[{ }^{11} \mathrm{C}\right] \mathrm{PIB}$ uptake in Alzheimer disease. Neurology. 2006;67: 1575-1580.

6. Edison P, Archer HA, Hinz R, et al. Amyloid, hypometabolism, and cognition in Alzheimer disease: an $\left[{ }^{11} \mathrm{C}\right] \mathrm{PIB}$ and $\left[{ }^{18} \mathrm{~F}\right] \mathrm{FDG}$ PET study. Neurology. 2007;68: 501-508.

7. Fagan AM, Mintun MA, Mach RH, et al. Inverse relation between in vivo amyloid imaging load and cerebrospinal fluid $A \beta_{42}$ in humans. Ann Neurol. 2006;59:512-519.

8. Archer HA, Edison P, Brooks DJ, et al. Amyloid load and cerebral atrophy in Alzheimer's disease: an ${ }^{11} \mathrm{C}$-PIB positron emission tomography study. Ann Neurol. 2006;60:145-147.

9. $\mathrm{Ng} \mathrm{S}$, Villemagne VL, Berlangieri S, et al. Visual assessment versus quantitative assessment of ${ }^{11} \mathrm{C}$-PIB PET and ${ }^{18} \mathrm{~F}$-FDG PET for detection of Alzheimer's disease. J Nucl Med. 2007;48:547-552.

10. Mintun MA, Larossa GN, Sheline YI, et al. $\left[{ }^{11} \mathrm{C}\right] \mathrm{PIB}$ in a nondemented population: potential antecedent marker of Alzheimer disease. Neurology. 2006; 67:446-452.

11. Villemagne VL, Pike KE, Darby D, et al. Abeta deposits in older non-demented individuals with cognitive decline are indicative of preclinical Alzheimer's disease. Neuropsychologia. 2008;46:1688-1697. 
12. Fodero-Tavoletti MT, Smith DP, McLean CA, et al. In vitro characterization of Pittsburgh compound-B binding to Lewy bodies. J Neurosci. 2007;27:1036510371.

13. Mathis CA, Wang Y, Holt DP, et al. Synthesis and evaluation of ${ }^{11} \mathrm{C}$-labeled 6-substituted 2-arylbenzothiazoles as amyloid imaging agents. J Med Chem. 2003;46:2740-2754.

14. Hyman BT, Trojanowski JQ. Consensus recommendations for the postmortem diagnosis of Alzheimer disease from the National Institute on Aging and the Reagan Institute Working Group on diagnostic criteria for the neuropathological assessment of Alzheimer disease. J Neuropathol Exp Neurol. 1997;56:10951097.

15. George AJ, Holsinger RM, McLean CA, et al. APP intracellular domain is increased and soluble $A \beta$ is reduced with diet-induced hypercholesterolemia in a transgenic mouse model of Alzheimer disease. Neurobiol Dis. 2004;16:124-132.

16. Tammer AH, Coia G, Cappai R, et al. Generation of a recombinant Fab antibody reactive with the Alzheimer's disease-related A $\beta$ peptide. Clin Exp Immunol. 2002;129:453-463.

17. McKhann G, Drachman D, Folstein M, et al. Clinical diagnosis of Alzheimer's disease: report of the NINCDS-ADRDA Work Group under the auspices of Department of Health and Human Services Task Force on Alzheimer's Disease. Neurology. 1984;34:939-944.

18. McKeith IG, Galasko D, Kosaka K, et al. Consensus guidelines for the clinical and pathologic diagnosis of dementia with Lewy bodies (DLB): report of the consortium on DLB international workshop. Neurology. 1996;47:1113-1124.

19. Friston KJ, Frith CD, Liddle PF, Frackowiak RS. Comparing functional (PET) images: the assessment of significant change. J Cereb Blood Flow Metab. 1991;11:690-699.

20. Logan J, Fowler JS, Volkow ND, et al. Distribution volume ratios without blood sampling from graphical analysis of PET data. J Cereb Blood Flow Metab. 1996; 16:834-840.

21. Price JC, Klunk WE, Lopresti BJ, et al. Kinetic modeling of amyloid binding in humans using PET imaging and Pittsburgh Compound-B. J Cereb Blood Flow Metab. 2005;25:1528-1547.

22. Culvenor JG, McLean CA, Cutt S, et al. Non-A $\beta$ component of Alzheimer's disease amyloid (NAC) revisited: NAC and alpha-synuclein are not associated with Aß amyloid. Am J Pathol. 1999;155:1173-1181.

23. Klunk WE, Debnath ML, Pettegrew JW. Chrysamine-G binding to Alzheimer and control brain: autopsy study of a new amyloid probe. Neurobiol Aging. 1995; $16: 541-548$.
24. Klunk WE, Wang Y, Huang GF, et al. The binding of 2-(4'-methylaminophenyl)benzothiazole to postmortem brain homogenates is dominated by the amyloid component. J Neurosci. 2003;23:2086-2092.

25. Joachim CL, Morris JH, Selkoe DJ. Diffuse senile plaques occur commonly in the cerebellum in Alzheimer's disease. Am J Pathol. 1989;135:309-319.

26. Mathis $\mathrm{CA}$, Wang $\mathrm{Y}$, Klunk WE. Imaging $\beta$-amyloid plaques and neurofibrillary tangles in the aging human brain. Curr Pharm Des. 2004;10:1469-1492.

27. Roher AE, Kuo YM, Esh C, et al. Cortical and leptomeningeal cerebrovascular amyloid and white matter pathology in Alzheimer's disease. Mol Med. 2003;9: $112-122$.

28. Lockhart A, Lamb JR, Osredkar T, et al. PIB is a non-specific imaging marker of amyloid-beta (Aß) peptide-related cerebral amyloidosis. Brain. 2007;130:26072615.

29. Tanaka S, Nakamura S, Kimura J, Ueda K. Age-related change in the proportion of amyloid precursor protein mRNAs in the gray matter of cerebral cortex. Neurosci Lett. 1993;163:19-21.

30. Storey E, Cappai R. The amyloid precursor protein of Alzheimer's disease and the A $\beta$ peptide. Neuropathol Appl Neurobiol. 1999;25:81-97.

31. Chen XH, Siman R, Iwata A, et al. Long-term accumulation of amyloid- $\beta$, $\beta$-secretase, presenilin-1, and caspase- 3 in damaged axons following brain trauma. Am J Pathol. 2004;165:357-371.

32. Salat DH, Kaye JA, Janowsky JS. Prefrontal gray and white matter volumes in healthy aging and Alzheimer disease. Arch Neurol. 1999;56:338-344.

33. Lee BC, Mintun M, Buckner RL, Morris JC. Imaging of Alzheimer's disease. J Neuroimaging. 2003;13:199-214.

34. Stahl R, Dietrich O, Teipel SJ, et al. White matter damage in Alzheimer disease and mild cognitive impairment: assessment with diffusion-tensor MR imaging and parallel imaging techniques. Radiology. 2007;243:483-492.

35. Chalmers K, Wilcock G, Love S. Contributors to white matter damage in the frontal lobe in Alzheimer's disease. Neuropathol Appl Neurobiol. 2005;31:623-631.

36. Chou YC, Teng MM, Guo WY, et al. Classification of hemodynamics from dynamic-susceptibility-contrast magnetic resonance (DSC-MR) brain images using noiseless independent factor analysis. Med Image Anal. 2007;11:242-253.

37. Ibaraki M, Shimosegawa E, Toyoshima H, et al. Effect of regional tracer delay on $\mathrm{CBF}$ in healthy subjects measured with dynamic susceptibility contrastenhanced MRI: comparison with ${ }^{15}$ O-PET. Magn Reson Med Sci. 2005;4:27-34.

38. Ichise M, Golan H, Ballinger JR, et al. Regional differences in technetium-99mECD clearance on brain SPECT in healthy subjects. J Nucl Med. 1997;38:12531260. 